ПОМИГУЕВ Илья Александрович - кандидат политических наук; научный сотрудник отдела политической науки Института научной информации по общественным наукам РАН (117218, Россия, 2. Москва, ул. Кржижановского 15, корп. 2; ротіlyа@таil.ru); старший преподаватель департамента политологии и массовых коммуникаций Финансового университета при Правительстве РФ (125993, Россия, г. Москва, Ленинградский пр-кт, 49)

\title{
ОСОБЕННОСТИ СЕТЕВОГО ПОДХОДА К ИЗУЧЕНИЮ СООБЩЕСТВА МОЛОДЫХ ПОЛИТОЛОГОВ
}

Аннотация. В статье рассматриваются особенности изучения сообщества молодых политологов, формулируются основные проблемы их идентификации и роли в политической сфере. Автор отмечает базовые принципы применения сетевого подхода для исследования сообщества, а также анализирует характеристики научного знания о политике как основного ресурса сетевых отношений молодых политологов. Ключевые слова: политическая наука, научные сети, научные коммуникации, научное сообщество, молодые политологи, научное знание.

\section{Сообщество молодых политологов}

Молодые политологи ${ }^{1}$ - это особая социальная группа, которая в силу возраста и специфики получаемых знаний имеет высокий потенциал непосредственного участия в политических процессах. Их роль в политической жизни может быть различной - от ученого до публичного политика, от аналитика до лоббиста; при этом четко определить социальные позиции политологов, особенно молодых, а также идентифицировать их по профессиональному признаку достаточно сложно, особенно если разделять научную и практическую деятельность представителей этой профессии ${ }^{2}$.

Проблеме вовлеченности ученых в политику посвящено достаточно много работ, но взгляды исследователей порой диаметрально противоположны. Например, позитивисты и бихевиоралисты считают, что ученый должен оставаться сторонним наблюдателем, марксисты отмечают «объективные законы» социального развития, которые определяют активную включенность в политическую борьбу представителей науки. Постбихевиоралисты попытались найти «золотую середину»: Д. Истон считает, что наука должна существовать не ради науки, а ради улучшения общества, конструирования новой, лучшей социальной реальности; соответственно, ученые несут ответственность за продвигаемые идеи, и сами в какой-то степени становятся политиками [Easton 1969].

Предметом постоянной саморефлексии научного сообщества являются

1 Под понятием «молодой политолог» мы будем понимать «студентов, аспирантов и молодых ученых, обучающихся по специальности политология и смежным наукам, занимающихся преподаванием дисциплин и исследованиями в области политической науки». Источник: Положение о Совете молодых политологов РАПН. - Сайт РАПН. Доступ: https://rapn.ru/in.php?part=in\&gr=11 $\& \mathrm{~d}=1845 \& \mathrm{n}=35 \& \mathrm{p}=0 \&$ to=about. Понятие «молодой ученый» нормативно закреплено. Это работник образовательной или научной организации, имеющий ученую степень кандидата наук в возрасте до 35 лет или ученую степень доктора наук в возрасте до 40 лет, <... либо являющийся аспирантом, исследователем или преподавателем образовательной организации высшего образования без ученой степени в возрасте до 30 лет. Источник: Распоряжение Правительства РФ от 29.11.2014 N 2403 -р «Об утверждении Основ государственной молодежной политики Российской Федерации на период до 2025 года». Доступ: http://www.consultant.ru/document/cons_doc_LAW_171835/259d15e3e1e1cdf340516 51764c142ec83e16404/

2 Например, в статье показано, что молодые политологи, занимаясь наукой, оказываются более политически активными, чем их сверстники - не-политологи [Барсегян 2018]. 
вопросы определения профессионального портрета российских политологов [Пляйс 2009; Политическая наука... 2008; Малинова 2015], а также профессиональной идентичности, восприятия их внешней средой - обществом и государством. Еще в 2003 г. состоялась конференция профессиональных ассоциаций в области общественных наук, где поднимались вопросы самоорганизации «взрослых» профессиональных сообществ, перспективы их развития и влияния на научно-преподавательскую деятельность [Профессиональные ассоциации... 2003]. Интересно, что образование не является единственным (или даже главным) критерием принадлежности к данной профессиональной группе. Политологами считаются люди, занимающиеся исследовательской, аналитической, преподавательской деятельностью, связанной с политической наукой [Малинова 2006], но не только. Ими могут быть аналитики, политтехнологи, идеологи, лоббисты, партийные деятели и т.д.

В 2008 г. авторы эмпирического исследования РАПН при этом определили дистанцирование исследователей и преподавателей от политических комментаторов, медиаперсон, а также представителей других гуманитарных специальностей по профессиональному принципу, хотя и отметили, что российская политическая наука сохраняет в целом свою приверженность междисциплинарности [Малинова 2015].

Определение понятия «сообщества» также имеет ряд особенностей. К. Кэлхун предложил сразу несколько формулировок: это группы, образованные по общности характеристик (социальных, юридических и др.); малые группы, сформированные на межличностных отношениях по сетевому признаку; люди, включенные в общий дискурс изучения социальных институтов [Calhoun 1999]. Однако вполне можно учитывать все эти характеристики при изучении сообщества политологов, поскольку мы можем одновременно наблюдать процессы институционализации науки и профессии политолога, формирование малых групп по горизонтальному принципу, а также общую направленность на получение знаний о природе политического. Звучит также точка зрения, что ближе всего к «идеальному типу сообщества» приближаются социальные группы, основанные на идентичностях, чувстве принадлежности, общности интересов, которые складываются в процессе социализации индивидов [Сообщества... 2009: 118].

Можно также определять научные сообщества еще шире - как интеллектуальные, выделяя их основную цель в виде производства новых смыслов, социально значимых форм [Сообщества... 2009: 190]. И в данном случае молодые люди, не ограниченные жесткими рамками прошлого научного бэкграунда, могут выступить движущей силой изменений в умах людей и бросить вызов устоявшимся научным теориям и практикам.

При этом связь молодых политологов с «взрослым» научным сообществом может быть затруднена в силу возраста, неопытности, отсутствия формальных признаков, например ученой степени, неопределенности профессиональных целей, низкой мобильности и т.д.

В свою очередь, образовательные организации, особенно региональные, часто ограничены в возможности обеспечить формирование широких научных сетевых коммуникаций в сообществе (отечественном и международном) для получения главного ресурса - знаний о политическом. Развитие сетевых контактов позволяет оставаться в сообществе и после окончания обучения, служит для молодых людей стимулом для продолжения профессиональной деятельности в политической сфере. Причем нужно учитывать современные особенности коммуникаций в контексте процессов глобализации, тенденций к «размыванию» границ, цифровому развитию, когда формируются образовательная 
и научная «глобальные деревни», интернационализируются и интенсифицируются профессиональные взаимодействия, где главным капиталом становятся информация и знания.

Появляется потребность в комплексном исследовании нового поколения политологов, причем изучении не столько институтов образовательного процесса, сколько процесса выстраивания коммуникаций в ходе их обучения и обретения ими профессиональных знаний. Каким образом можно изучать такое сообщество?

\section{Сетевой подход к изучению сообщества молодых политологов}

Наиболее перспективным для изучения сообществ выглядит использование методологии сетевого подхода, в настоящее время получившего большую популярность в социальных науках. Междисциплинарная методология сетевого анализа является одним из наиболее удачных подходов для рассмотрения отношений и взаимодействий социальных групп [Scott 2000], в т.ч. молодежи [Кучукян 2017]. Уже к 20-м гг. XX в. социологи (Г. Зиммель, Дж. Морено, Э. Дюркгейм и др.), психологи (С. Милграм, Ф. Хейдер, Т. Нькомб и др.), антропологи (А.Р. Рэдклифф-Браун, Дж.К. Митчелл и др.) [Сушко 2015] отмечали особую роль сетевых форм взаимодействия. С развитием компьютерных технологий (с 1970-х гг.) информатики, математики (теория графов) статистические физики также проявляли интерес к исследованию больших сетей.

Стоит отметить, что сетевой подход использовался еще в СССР в науковедческих работах, посвященных роли научных сетей в организации фундаментальных исследований. В 1987 г. вышла монография Г.Г. Дюментона, где рассматривались вопросы определения личных и общих научных целей, эффективности организации и управления научным коллективом, закономерности развития личных сетей и научных результатов, выявлялись типы научных связей и механизмы признания научных достижений [Дюментон 1987]. Переход в историческую фазу информационного общества, о котором писали еще Э. Тоффлер и М. Кастельс, показал важность изучения не только акторов, но и особенностей коммуникации, структуры связи между элементами социальной системы.

Особо стоит выделить экономическую науку, где методологию сетевого анализа активно используют, особенно в теории игр. Отметим вклад сотрудников лаборатории сетевых форм организации НИУ ВШЭ, которые подробно систематизировали методологические положения сетевого подхода для анализа организаций и социальных групп [Методология исследования... 2014].

Особенности методологии анализа политических сетей подробно изложили в своем учебнике Л.В. Сморгунов и А.С. Шерстобитов [Сморгунов, Шерстобитов 2018]. Сети в политике и управлении изучают Ф.Т. Алескеров, А.И. Соловьев, О.В. Михайлова, И.В. Мирошниченко, А.П. Кочетков и др., за рубежом Д. Нок, Д. Марш, Дж. Куклински, К. Прован, П. Кенис, Х. Компстон и др.

Наработки ученых имеют особую значимость для исследования сообщества молодых политологов: с одной стороны, - это будущие специалисты, имеющие специальные знания об устройстве политических явлений и процессов и способные обеспечивать экспертное сопровождение процесса принятия политических решений. С другой - такие знания могут быть использованы в политической деятельности, причем без «отрыва от производства» научного продукта в виде исследований [Барсегян 2018]. Таким образом, молодых политологов так или иначе стоит считать реальным/потенциальным элементом политической сети. По классификации Р. Родса, представителя институциональной (организационной) теории, их можно отнести к профессиональным сетям, которые по своим характеристикам относительно изолированы 
от других групп, имеют общую идентичность и интересы [Rhodes 1997]. Сети молодых политологов предлагается рассматривать как научные, поскольку основным ресурсом сетевого обмена является объективное знание о политике, получаемое как из научной литературы, учебников, курсов лекций, так и из практической деятельности.

Основная методологическая проблема состоит в отличиях содержания и структуры этого знания о политике в зависимости от целей деятельности акторов и приобретения этих знаний, что приводит к разнице структуры, параметров, ресурсов сетей, механизмов коммуникации и основных целей молодых политологов. Именно поэтому предлагается сфокусировать внимание на научном знании как основном ресурсе сети молодежного политологического сообщества, которым в идеале должны овладеть все участники для рационального решения целей и задач, стоящих перед отдельным индивидом и сетевой организацией.

\section{К вопросу о научном знании как ресурсе сетевых отношений}

«Наука по определению является коллективным предприятием. Как бы гениальны ни были прозрения и достижения талантливых одиночек, приращение “систематических знаний о современном мире” - результат деятельности сообществ ученых» [Политическая наука... 2008: 440]. Эти слова как нельзя точно формулируют смысл существования научных сообществ, в т.ч. политологов. Однако возникает вопрос: что считать научным знанием в сетевом взаимодействии?

Мы предлагаем исходить из классической традиции социологии науки, идущей от Р. Мертона и его школы, дополненной затем системной социологией науки Н. Лумана, Р. Штихве, В. Патцельта и др. и разделяемой также многими российскими исследователями [The Cambridge History... 2008; Этос науки... 2008]. Наука здесь рассматривается как познавательная деятельность в рамках определенной социальной институционализации. Это значит, что получение, накопление и трансляция знаний в науке обусловлены определенными социально-институциональными параметрами, вне которых знание утрачивает статус научного.

В данном случае изучение процесса получения, накопления и трансляции знания о политике невозможно без изучения институционализации профессиональных научных сообществ, в т.ч. политологических организаций. Такой подход позволяет исследовать научное знание в качестве самостоятельного, рационального и критического познания мира политического и в целом соответствует разработкам современных ученых, исследующих менеджмент знаний (Т. Давенпорт, К. Свейби, К. Виг и др.) [Handbook on... 2003]. Однако нужно учитывать, что строгость подхода к получению научного знания о политике может иметь обратный эффект, поскольку «чем больше политическая наука стремится быть объективной и строиться по меркам естественнонаучного знания, тем меньший интерес она вызывает в политическом мире» [Сморгунов 2019: 78].

Научное знание о сфере политического независимо от дальнейших карьерных траекторий молодых политологов все равно является для них базовым ресурсом, позволяющим развиваться профессионально как минимум в четырех направлениях: наука ради науки; косвенное/прямое участие в политике; деятельность, не связанная с политикой. Так или иначе молодые специалисты осознают свою принадлежность к политологическому сообществу, если получили или получают углубленные научные знания о политике.

Сетевой подход предполагает изучение отношений между акторами сети (в 
данном случае - молодыми политологами), имеющими принадлежность к своему сообществу, определяемую обучением в образовательных учреждениях по политологическим специальностям, участием в профессиональных организациях, а также занятием научной деятельностью. В процессе коммуникации происходит взаимный обмен знаниями на основе рационального выбора акторов, формирующий социальный и интеллектуальный капитал сети, а молодежные политологические организации являются одним из субъектов такого процесса наряду с вузами. Приоритет в сетевом подходе отдается при этом не индивидуальным предпочтениям акторов или характеристикам отдельных институтов, а сетевым отношениям.

Отметим также, что основным методом взаимодействия и координации сетевых отношений является сотрудничество, которое построено на трех базовых принципах: это наличие совместных задач, обмен сетевыми ресурсами, установление доверительных отношений в ходе постоянного сотрудничества [Сморгунов 2015: 22].

В современных условиях жестких ограничений норм и традиций личного взаимодействия может и не быть: часто люди проживают далеко друг от друга, имеют разный социальный статус, при этом формулируют сходные цели в процессе получения политологического знания. Именно поэтому институционально сложно оценить коалиции независимых акторов, составляющих сеть. Как точно подчеркивает О.В. Михайлова в своей докторской диссертации, «сеть - это пример современной, постмодернистской организации, которую отличает локация не по месту, а по времени» [Михайлова 2014: 33].

Значение институтов умалять все же не стоит. Например, молодежные политологические организации также являются элементом научной сети, поскольку способствуют идентификации молодых политологов с научным сообществом, выстраиванию доверительных и плотных профессиональных связей, обеспечивают сплоченность. Анализ деятельности организаций позволит определить внутренние ресурсы сетевой структуры в контексте их отношений с другими организациями, в т.ч. образовательными.

Отметим также, что любая сеть не может существовать в отрыве от окружающей среды как совокупности факторов, оказывающих на нее воздействие [Сморгунов, Шерстобитов 2018: 52]. Существование и развитие сети напрямую зависит от того, как она сможет отвечать на внешние вызовы - социальные, политические, экономические, технологические и т.д. Значимым также является институциональный фактор, формулирующий правила игры и определяющий стратегии и возможности выстраивания сетевых отношений. Таким образом, важным элементом сетевого анализа является анализ контекста сетевых взаимодействий молодых политологов.

\section{Заключение}

Исследование сообщества молодых политологов имеет ряд особенностей, без учета которых раскрыть его содержание и характеристики будет довольно сложно. В первую очередь это проблема вовлеченности молодых ученых и специалистов в политику, соединение ролей теоретиков и практиков в профессиональной жизни. От этого будет зависеть и профессиональный портрет политологов, особенности их идентичности и восприятия внешней средой. Так или иначе цель деятельности политологов как представителей интеллектуального сообщества заключается в производстве новых смыслов и идей, социально значимых форм ради улучшения общества, что в определенной мере делает их политиками.

Понятие «сообщество» также достаточно сложно и многогранно, но точно 
можно сказать лишь, что оно формируется в процессе институционализации науки и профессии политолога, формирования малых групп по сетевому (горизонтальному) признаку и цели - получить знания о политическом. Если отталкиваться от таких характеристик, наиболее перспективным методологическим подходом исследования становится сетевой анализ, который позволяет оценить особенности коммуникации и структуры связи между элементами социальной системы. Основным ресурсом сетевого обмена является объективное знание о политике, структура и содержание которого отличаются.

Наука - дело коллективное. Получение, накопление и трансляция знаний в науке обусловлены определенными социально-институциональными параметрами. Научное знание о сфере политического независимо от дальнейших карьерных траекторий молодых политологов все равно является для них базовым ресурсом, позволяющим развиваться профессионально в рамках сетевого взаимодействия. При этом институционализированные субъекты (образовательные и профессиональные организации) выступают полноценными участниками сети, способствующими ее развитию.

Статья подготовлена при финансовой поддержке РФФИ и АНО ЭИСИ в рамках научного проекта № 19-011-33052.

\section{Список литературы}

Барсегян В.М. 2018. Политическая и научная активность молодых политологов: Игра с нулевой суммой? - Политическая наука. № 4. С. 258-270.

Дюментон Г.Г. 1987. Сети научных коммуникаций и организация фундаментальных исследований (отв. ред. В.А. Ядов). АН СССР, Ин-т истории естествознания и техники. М.: Наука. 103 с.

Кучукян А.В. 2017. Возможности методологии сетевого анализа в исследовании виртуальных молодежных сообществ. - Теория и практика общественного развития. № 4. С. 24-26.

Малинова О.Ю. 2006. Об опыте взаимодействия профессионального сообщества политологов с властью и гражданскими организациями. - Публичная политика (под ред. А.Ю. Сунгурова). СПб: Норма. С. 42-54.

Малинова О.Ю. 2015. Кто формирует общественное «лицо» профессии: сравнительный анализ репрезентации «политологов», «экономистов» и «историков» в российских печатных СМИ. - Политическая наука. № 3. С. 225-237.

Методология исследования сетевых форм организации бизнеса: коллективная монография (М.А. Бек, Н.Н. Бек, Е.В. Бузулукова и др.; под науч. ред. М.Ю. Шерешевой). 2014. М.: ИД ВШЭ. 446 с.

Михайлова О.В. 2014. Сетевая архитектура государственного управления: проблемы концептуализации и практики: дис. ... д.полит.н. М.: МГУ им. М.В. Ломоносова. 335 с.

Пляйс Я.А. 2009. Политология в контексте переходной эпохи в России. М.: РОССПЭН. 448 с.

Политическая наука в России: проблемы, направления, школы (1990-2007) (редкол.: С.В. Патрушев, Я.А. Пляйс, В.В. Смирнов; отв. ред. О.Ю. Малинова). 2008. М.: РАПН; РОССПЭН. 463 с.

Профессиональные ассоциации в России и оптимизация условий научной и преподавательской деятельности: материалы конференции. Центр развития политической науки и конституционного права. 2003. М.: ИНИОН РАН. 246 с.

Сморгунов Л.В. 2015. Политическая интеграция в сетевом обществе: поиск нового порядка для инклюзивного развития. - Вестник СПбГУ. Сер. 6. Вып. 4. C. $12-25$. 
Сморгунов Л.В. 2019. Познание политической реальности: от состояния политики к политическим процессам. - Политика и управление государством: новые вызовы и векторы развития (под ред. А.И. Соловьева, Г.В. Пушкаревой). М.: Аспект-Пресс. С. 76-93.

Сморгунов Л.В., Шерстобитов А.С. 2018. Политические сети: теория и методы анализа: учебник. М.: Аспект Пресс. 320 с.

Сообщества как политический феномен (под ред. П.В. Панова, К.А. Сулимова, Л.А. Фадеевой). 2009. М.: РОССПЭН. 248 с.

Сушко В.А. 2015. История и методология сетевого подхода. - Социология. № 1. C. 46-58.

Этос науки: коллективная монография (отв. ред. Л.П. Киященко, Е.3. Мирская). 2008. М.: Academia. 544 с.

Calhoun C. 1999. Nationalism, Political Community and the Representation of Society or Why Feeling at Home Is not a Substitute for Public Space. - European Journal of Social Theory. Vol. 2. No. 2. P. 217-231.

Easton D. 1969. The New Revolution in Political Science. - American Political Science Review. Vol. 63. No. 4. P. 1051-1061.

Handbook on Knowledge Management 2. Knowledge Directions (ed. by C.W. Holsapple). 2003. Springer. $751 \mathrm{p}$.

Rhodes R. 1997. Understanding Governance. Policy Network, Governance, Reflexivity and Accountability. Buckingham, Philadelphia: Open University Press. 252 p.

Scott J. 2000. Social Network Analysis: a handbook. $2^{\text {nd }}$ edition. L.: SAGE Publications Ltd. 224 p.

The Cambridge History of Science. Vol. 7: The Modern Social Sciences (ed. by T. Porter, D. Ross). 2008. Oxford: Cambridge University Press. 734 p.

POMIGUEV II'ya Aleksandrovich, Cand.Sci. (Pol.Sci.), Researcher of Political Science Department, Institute of Information on Social Sciences, Russian Academy of Sciences (15 Krzhizhanovskogo St, Moscow, Russia, 117218); Senior Lecture at the Department of Political Science and Mass Communication, Financial University under the Government of the Russian Federation (49 Leningradsky Ave, GSP-3, Moscow, Russia, 125993; pomilya@mail.ru)

\section{YOUNG POLITICAL SCIENTISTS COMMUNITY STUDY: NETWORK APPROACH}

Abstract. The article considers the features of studying the young political scientists community, formulates the main problems of their identification and role in the political sphere. The author draws attention to the basic principles of applying the network approach to community research and analyzes the characteristics of scientific knowledge about politics as the main resource of network relationship of young political scientists community.

Keywords: political science, scientific networks, science communication, science community, young political scientists, scientific knowledge 